\title{
Impact of cognitive stimulation on depression, anxiety, cognition and functional capacity among adults and elderly participants of an open university for senior citizens
}

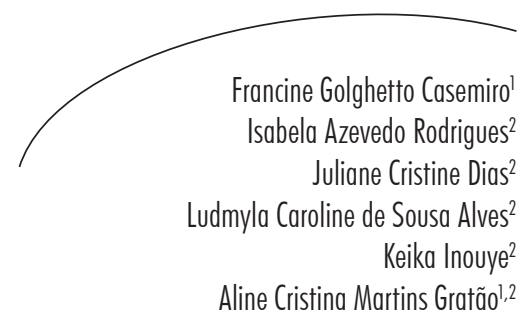

Abstract

Objective: this study evaluated the effectiveness of a Gerontological Cognitive Stimulation workshop, aimed at improving the cognitive and functional performance and mood symptoms of senescent participants in an Open University for Senior Citizens. Method: An open controlled clinical trial with a wait list was performed, with 15 people participating in the intervention group and 16 people in the control group. At the beginning and end of the study (six months later) the Digit span, ACE-R, Anxiety Inventory and Beck Depression, and Functional Independence Measure (FIM) tests were applied. Results: In the intervention group, there was improvement in the variables evaluated, with significant differences in the visuospatial domain $(p=0.022)$, symptoms of depression $(p=0.048)$

Key words: Elderly; Cognition; Depression; Anxiety and anxiety $(p=0.002)$. In the control group the symptoms of depression and anxiety deteriorated. Conclusion: The results suggest that the cognitive stimulation program has a beneficial effect on the mood symptoms of adults and elderly members of an Open University Program for Senior Citizens.

\footnotetext{
Universidade Federal de São Carlos, Programa de Pós-Graduação em Enfermagem. São Carlos, SP, Brasil

Universidade Federal de São Carlos, Departamento de Gerontologia. São Carlos, SP, Brasil 


\section{INTRODUCTION}

Maintaining cognition is important for the independence of elderly individuals, and its stimulation can prevent or delay the degenerative process in the brain. ${ }^{1}$ As the science and practice of care for the elderly, gerontology can and should strive not only to avoid or delay illness, but also to promote healthy aging, which requires maintaining and strengthening the physical and psychic functions of the elderly, as well as their social engagement in productive activities and significant interpersonal relationships. ${ }^{2}$

Cognitive stimulation workshops train individuals to live with, accept, reduce and overcome cognitive deficits, as well as to value the personal desires, subjectivities and life stories of each participant. The goal of these workshops is to improve the quality of life of the participants. ${ }^{3}$ The workshops involve performing different types of exercises, which seek to improve or compensate for deficits. These exercises include word memorization (to train the memory), searching for differences between images (to train attention to detail) and the completion of puzzles (to train constructive capacity), among others. ${ }^{4}$

In Brazil, Yassuda et al. ${ }^{5}$ sought to confirm the effects of four sessions of an episodic memory stimulation program on 69 healthy elderly individuals. The post-test results showed that the individuals in the experimental group performed better, in terms of remembering the text and using memory strategies, than those in the control group.

In the Netherlands, Valentijn et al. ${ }^{6}$ studied healthy elderly individuals with subjective memory complaints, seeking to determine the effects of two different types of memory stimulation (collective and individual). The results showed that, after the intervention, the participants of the collective training group exhibited more stability, less anxiety and less stress related to memory function.

Affective factors are believed to play an important role in cognitive performance. Consequently, these variables should be measured in studies of cognitive stimulation. The correlation between depressive states and cognitive performance is well known. ${ }^{7}$ Thus, it is plausible that a decrease in depressive symptoms, as a result of participation in group training sessions, could be responsible for the improvement in performance after training. ${ }^{5}$

It has been reported that the provision of a stimulating and collective environment can lead to social inclusion and improved cognition in several domains. This hypothesis was argued by Marioni et al. ${ }^{8}$ who assessed engagement in social, physical and intellectual activities, as well as social support, the self-perception of how well one is understood, and the degree of satisfaction with social relationships among 2854 elderly individuals in France. The authors used a longitudinal study and correlated these factors with incident dementia and cognitive alterations over a period of 20 years. The research showed that there was a correlation between engagement in social, physical and intellectual activities and increased (or stable) cognitive capacity.

In Brazil, the study of cognitive stimulation (CS) in old age is in its initial stages and has received little attention from researchers. It is believed that satisfactory cognitive function is essential so that the elderly can continue to live independently and maintain their quality of life. Thus, the search for gerontological interventions, such as cognitive training workshops, is extremely important for the promotion of physical, psychic and emotional health, as well as the prevention of problems related to cognitive deficits and the social inclusion of these individuals.

Therefore, the aim of the present study was to determine the effects of CS on the cognition, mood and functional capacity of adults and elderly individuals who actively participated in a permanent education program in the Universidade Aberta à Terceira Idade - Fundação Educacional de São Carlos (Open University for Senior Citizens of the de São Carlos Educational Foundation) (UATI-FESC) through pre- and post-intervention assessments.

\section{METHOD}

This research involved an open, controlled clinical trial with a wait list. The base population 
for the samples from the experimental and control groups was composed of participants in the Universidade da Terceira Idade de São Carlos (São Carlos Open University for Senior Citizens) (UATI/FESC). The UATI/FESC has been in operation for 20 years and is a community-based public project of the Fundação Educacional São Carlos (São Carlos Educational Foundation) (FESC), which seeks to educate adults and elderly individuals through permanent courses in health, culture, sport, leisure, citizenship and work. ${ }^{8}$

In 2013, the population base of the UATI/ FESC was 458, and the participants exhibited very similar characteristics to the populations of other Universities for Senior Citizens (USCs) in Brazil: mostly female ( $92 \%$ ); with a mean age of $63.3 \pm 10.4$ years. The oldest participant was 89 years old and the youngest was 40 years old. The majority of these individuals are middle class and their education levels vary (from illiterate individuals to those with doctorate qualifications).?

The subjects were selected as follows: the cognitive stimulation (CS) gerontological workshop was advertised and 40 individuals expressed an interest in participating. These individuals $(\mathrm{n}=40)$ were assessed in line with the study protocol. After this assessment, the first group of interested parties (20) completed the workshop and made up the Intervention Group (IG). The second group $(\mathrm{n}=20)$ was placed on a wait list for another workshop and was called the Control Group (CG).

Based on the inclusion and exclusion criteria, five participants were excluded from the IG as they did not complete $75 \%$ of the workshop. Four individuals were excluded from the CG as they were under 50 years of age. Therefore, 31 subjects were divided into two groups: the IG contained 15 individuals who participated in the CS workshop and the CG contained 16 individuals who did not participate in the workshop (wait list).

Inclusion criteria: individuals aged 50 years or more (confirmed by valid Brazilian identity documents) who were present for at least $75 \%$ of the workshop.

Exclusion criteria: severe visual or auditory deficits that would hinder the understanding of the individual of the workshop and tests; a severe clinical comorbidity; or a cognitive deficit, as measured by the ACE-R (less than 78 points). Figure 1 displays a fluxogram of the participants.

All stages of this research followed the guidelines contained in resolutions $466(12 / 12 / 2012)$ and 251 (07/08/97) of the Conselho Nacional de Saúde (Brazilian National Health Council). The present study received approval from the Human Research Ethics Committee of the Universidade Federal de São Carlos (São Carlos Federal University) under protocol number 874.213/2014.

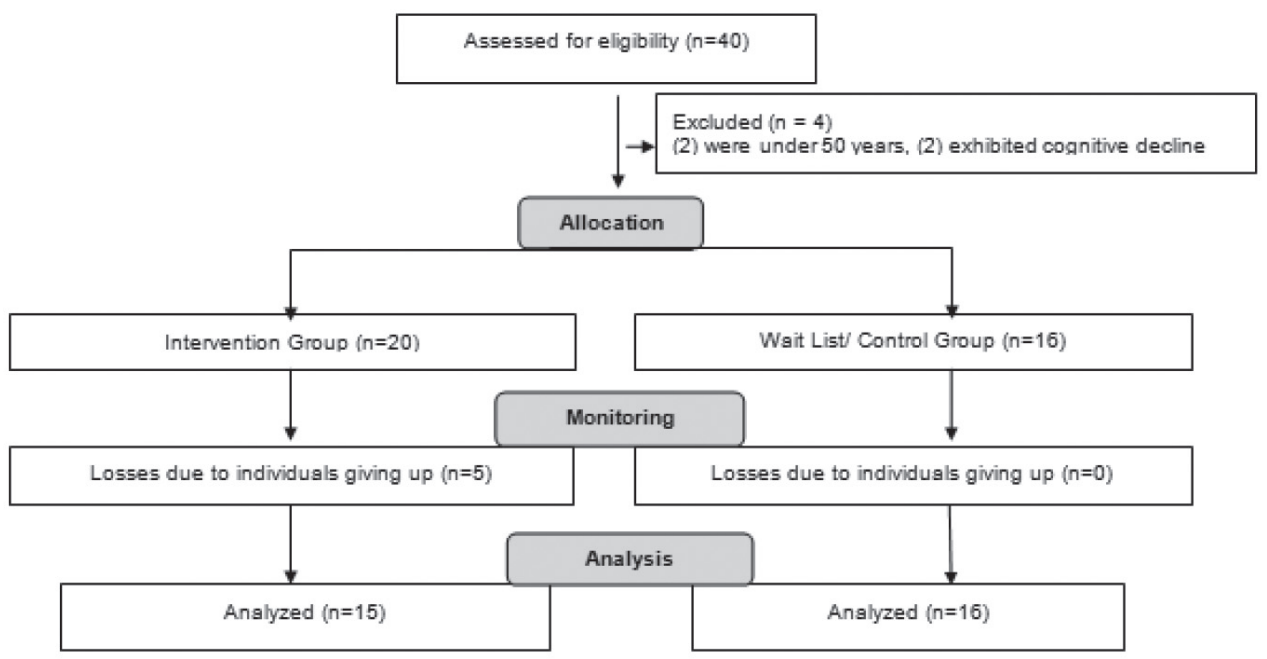

Figure 1. Fluxogram of the participants. São Carlos, 2015. 
Assessment of the subjects

An interview was conducted with the participants and an assessment protocol was applied, including a sociodemographic profile questionnaire (gender, age, education, marital status, occupation). In addition, pre- and postintervention assessments were completed using the instruments described below.

Addenbrooke's Cognitive Examination-Revised (ACE-R) ${ }^{10}$ was used for the cognitive assessment. This examination seeks to assess six cognitive domains separately: orientation; attention; memory; verbal fluency; language and visual-spatial ability. The maximum score is 100 points, and the sum of all points scored equals the total score of the individuals in the ACE. The 30 points related to the Mini Mental State Examination (MMSE) are included in this score. Cutoff points for the full battery of tests and the MMSE (ACE-R) were set at $<78$ points and $<25$ points, respectively. ${ }^{11}$

The aim of the digit span task is to assess the short-term storage capacity of the memory and its executive component, particularly when the digits are counted in reverse order. ${ }^{12}$

The Beck Anxiety inventory (BAI) was used to record symptoms of anxiety. This inventory was validated for use in Brazil by Cunha ${ }^{13}$ and involves a list of 21 common symptoms of anxiety, with options for each, representing increasing levels of anxiety: 0-10 points, minimum symptoms or absence of anxiety; 11-19, mild; 20-30, moderate; and 31-63, severe. Anxiety is considered clinically significant for all scores above 10 points (mild to severe). ${ }^{13-14}$

The Beck Depression Inventory (BDI) is a symptomatic depression scale. It involves a questionnaire with 21 items, with four options ranging from $0-3$ points. The sum of the points provides a total score which indicates the intensity of the depression, as follows: 0 to 9 points - minimum symptoms or absence of symptoms; 10 to 18 points - mild symptoms; 19 to 29 points - moderate symptoms; and 30 to 63 points - severe depression symptoms. ${ }^{13-14}$

The Functional Independence Measure (FIM) ${ }^{15}$ seeks to assess the incapacity of patients with functional restrictions (varied sources). The FIM uses the following classifications: total dependence (total assistance) $=18$ points; maximum dependence (assistance up to $75 \%$ in a task) and moderate dependence (assistance up to 50\% in a task) $=19$ 60 points; minimum dependence (assistance up to $25 \%$ in a task) and supervision, stimulation or preparation $=61-103$; modified and complete independence $=104-126$ points.

Intervention: The CS workshop was planned based on data recorded from other sites that had used this type of approach, as well as other courses conducted in the area and the guidance of relevant professionals. The games were purchased after receiving financial support from the partner project "Intervention strategies for elderly individuals with mildly impaired cognition" (process FAPESP 2014/18829-4). The chronogram began in the first semester of 2015, when activities began in the Universidade Aberta da Terceira Idade (FESC, campus I). In total, 20 sessions were completed at weekly meetings of one hour, over a period of six months. In order to ensure that the participants received all the protocol interventions, their presence was controlled by a call list. During the first weeks, the theory of cognition was addressed, followed by the application of cognitive games. A circuit of two or three activities per session was established so that the individuals would exercise different cognitive domains in all of the interventions. The control group (CG) was invited to participate in workshop number 20, which focused on recreational activities and socialization, in order to ensure that this group participated in at least one activity. Figure 2 displays a chronogram of the activities performed. 


\begin{tabular}{|c|c|c|c|}
\hline Workshop & EG & CG & Activities \\
\hline 1 & $\bar{x}$ & - & Music \\
\hline 2 & $\mathbf{x}$ & - & Modeling clay, dominoes, storytelling \\
\hline 3 & $\mathrm{x}$ & - & $\begin{array}{l}\text { Mind academy game "Face to face", manufactured by ESTRELA Ltda. The first letter of ohcases are written down and words are } \\
\text { formed using these letters. Tetra colors game, manufactured by Simque Adtefatgs de Madeira Ltda. }\end{array}$ \\
\hline 4 & $\mathrm{x}$ & - & Mind academy game "Focus", manufactured by ESTRELA Ltda. Tactile ability, colored sticks. \\
\hline 5 & $\mathbf{x}$ & - & Mind academy game "Spot the difference", manufactured by ESTRELA Ltda. Sudoku (total of 15) \\
\hline 6 & $\mathbf{x}$ & - & Word and figure association \\
\hline 7 & $x$ & - & Mind academy game "Face to face", manufactured by ESTRELA Ltda. Story telling. \\
\hline 8 & $\mathrm{x}$ & - & Olfactory abilities; memory game \\
\hline 9 & $\mathrm{x}$ & - & Dominoes; Mind academy game "Focus", manufactured by ESTRELA Ltda. \\
\hline 10 & $\mathrm{x}$ & - & Colored sticks; story reproduction \\
\hline 11 & $\mathrm{x}$ & - & Reading and interpretation; Mind academy game "Spot the difference", manufactured by ESTRELA Ltda. \\
\hline 12 & $\mathbf{x}$ & - & Connecting points to letters \\
\hline 13 & $x$ & - & Mind academy game "One by one", manufactured by ESTRELA. Ltda. Center attention \\
\hline 14 & $\mathrm{x}$ & - & Tactile abilities; writing alternate words with numbers \\
\hline 15 & $\mathrm{x}$ & - & Writing backwards; copying prescriptions \\
\hline 16 & $\mathbf{x}$ & - & Supermarket (shopping) list; training with change \\
\hline 17 & $\mathrm{x}$ & - & Assaciative memory; colored sticks; Tetra colors game; manufactured by Simque Artefatos de Madeira Ltda. \\
\hline 18 & $\mathrm{x}$ & - & Sum triangle; Hanoi tower, manufactured by Wood toys Ltda. \\
\hline 19 & $\mathrm{x}$ & - & Mind academy game "Spot the difference", manufactured by ESTRELA. Ltda. Sudoku (total of 15) \\
\hline 20 & $\mathrm{x}$ & $\mathrm{x}$ & Reading and interpretation; completing song lyrics; finish the workshop with songs, breakfast and fruit \\
\hline $\begin{array}{l}\text { Make-up } \\
\text { classes }\end{array}$ & & & Make-up classes for those who were absent \\
\hline
\end{tabular}

EG=Experimental Group; CG=Control Group.

Figure 2. Chronogram of the activities performed. São Carlos, 2015.

Data analysis was conducted by a professional statistician, using version 20.0 of the Statistical Package for Social Science (SPSS). This analysis involved descriptive and univariate statistics for both categorical (tables of frequency) and quantitative (measures of central tendency and variability) variables. The variables measured exhibited normal distribution values, according to the Kolmogorov-Smirnov test. The results for the mean cognition variables (ACE-R and MMSE), the ACE-R domains, the digit span test, as well as depression, anxiety and functional capacity in both groups were compared and analyzed before and after the intervention using the student's t-test for independent samples. The variables of gender, marital status and occupation were compared and analyzed for independent samples using Fisher's exact test. The level of statistical significance was set at $p<0.05$.

\section{RESULTS}

In general, the majority of the participants were elderly (60 years or more), female, married, highly-educated and retired. Table 1 displays the pairing of the groups according to the clinical and sociodemographic variables of the two groups. No diferences were found between the two groups in relation to the baseline of the variables studied. 
Table 1. General characteristics of the participants in the intervention and control groups. São Carlos,2015.

\begin{tabular}{|c|c|c|c|}
\hline \multirow{2}{*}{ Variables } & \multicolumn{2}{|c|}{ Group } & \multirow{2}{*}{ Bilateral p-value } \\
\hline & $\begin{array}{l}\text { Intervention } \\
\quad(\mathrm{n}=16)\end{array}$ & $\begin{array}{l}\text { Control } \\
(n-=15)\end{array}$ & \\
\hline \multicolumn{4}{|l|}{ Demographic variables } \\
\hline Gender - Female n $(\%)$ & $14(93.3 \%)$ & $15(93.8)$ & $0.962 * *$ \\
\hline Gender - Male n( $\%)$ & $01(6.7)$ & $01(6.2)$ & \\
\hline Age (mean $\pm \mathrm{sd})$ & $71.2 \pm 8.5$ & $69.1 \pm 11.6$ & $0.570^{*}$ \\
\hline 50 to 59 years $n(\%)$ & - & $04(25.0)$ & \\
\hline 60 to 69 years $n(\%)$ & $08(53.3)$ & $03(18.8)$ & \\
\hline 70 to 79 years $n(\%)$ & $04(26.7)$ & $06(37.5)$ & \\
\hline 80 years or more $n(\%)$ & $03(20.0)$ & $03(18.8)$ & \\
\hline \multicolumn{4}{|l|}{ Marital status $\mathrm{n}(\%)$} \\
\hline Companion & $06(40.0)$ & $10(62.5)$ & $0.062 * *$ \\
\hline No companion & $09(60.0)$ & $06(37.5)$ & \\
\hline Education \pm sd & $12.8 \pm 3.3$ & $12.6 \pm 4.3$ & $0.839 *$ \\
\hline $1-4$ years of education $n(\%)$ & $01(6.7)$ & $01(6.2)$ & \\
\hline $5-8$ years n $(\%)$ & $02(13.3)$ & - & \\
\hline 9 years or more $\mathrm{n}(\%)$ & $12(80.0)$ & $15(93.8)$ & \\
\hline Occupation - Active n(\%) & $03(20.0)$ & $04(25.0)$ & $0.124 * *$ \\
\hline Occupation - Retired n(\%) & $12(80.0)$ & $12(75.0)$ & $0.061^{* *}$ \\
\hline ACE- $R$ mean \pm sd & $89.3 \pm 4.0$ & $88.7 \pm 5.1$ & $0.464 *$ \\
\hline MMSE mean \pm sd & $27.9 \pm 1.9$ & $27.7 \pm 1.7$ & $0.785^{*}$ \\
\hline BDI mean \pm sd & $5.3 \pm 3.8$ & $5.4 \pm 3.6$ & $0.946^{*}$ \\
\hline BAI mean \pm sd & $5.8 \pm 4.7$ & $5.9 \pm 4.5$ & $0.946^{*}$ \\
\hline MIF mean \pm sd & $124.5 \pm 2.4$ & $125.1 \pm 1.0$ & $0.435^{*}$ \\
\hline
\end{tabular}

* students t-test for independent samples; ${ }^{* *}$ Fishers exact test; $s d=$ standard deviation.

When the before and after values were compared an improvement was recorded in all of the variables studied in the IG, with the exception of functional capacity, which remained the same. However, only depression $(p=0.048)$ and anxiety symptoms ( $p=0.002$ ) were significantly statistically different. In the CG, the variables also exhibited a discreet improvement, with the exception of depression and anxiety symptoms, which worsened when the before and after values were compared.
No statistically significant diferences were found in the CG (Table 2).

In terms of the distribution of the ACE-R domains, an improvement was recorded in the IG in all domains, with the exception of verbal fluency, which remained the same. Interestingly, the visual and spatial domain exhibited a statistically significant difference $(p=0.022)$ and a trend towards the total ACE-R score $(p=0.082)$. 
In the CG, there was a discreet improvement in the mean scores of the variables studied, with the exception of verbal fluency, which remained the same. However, no statistically significant diferences were found in this group.

Qualitative analysis of the results confirmed that the participants in the IG were excited by the activities offered in the interventions, particularly as they were grouped together with other individuals of a similar age, with similar social profiles and health conditions. They shared a space where they felt that their personal desires, subjectivities and life stories were valued. These considerations were reflected in the improvements recorded in their cognitive patterns, anxiety issues and mood. These findings are contrary to those of the CG, the participants of which remained on a wait list and did not have the opportunity to share these experiences. This was reflected in the discreet worsening recorded for their anxiety and depression symptoms.

Table 2. Descriptive and comparative analysis of the variables digit span task, mood and functional capacity according to the assessment period (before and after) for the intervention and control groups. São Carlos, 2015.

\begin{tabular}{|c|c|c|c|c|c|c|}
\hline \multirow{2}{*}{$\begin{array}{c}\text { Variables } \\
\text { mean } \pm \text { standard } \\
\text { deviation }\end{array}$} & \multicolumn{2}{|c|}{ INTERVENTION GROUP } & \multirow[b]{2}{*}{$p$ value } & \multicolumn{2}{|c|}{ CONTROL GROUP } & \multirow[b]{2}{*}{$p$ value } \\
\hline & BEFORE & AFTER & & BEFORE & AFTER & \\
\hline Digit span $\mathrm{DO}^{\dagger}$ & $5.8 \pm 1.0$ & $5.4 \pm 1.3$ & 0.290 & $5.1 \pm 1.5$ & $5.6 \pm 1.3$ & 0.323 \\
\hline Digit span $\mathrm{IO}^{\dagger}$ & $3.8 \pm 1.0$ & $4.3 \pm 1.2$ & 0.313 & $3.6 \pm 1.2$ & $3.7 \pm 1.1$ & 0.878 \\
\hline $\begin{array}{l}\text { Depression } \\
\text { Symptoms }\end{array}$ & $11.2 \pm 5.8$ & $5.3 \pm 4.8$ & $\underline{0.048}$ & $5.4 \pm 3.9$ & $5.9 \pm 4.6$ & 0.744 \\
\hline $\begin{array}{l}\text { Anxiety } \\
\text { symptoms }\end{array}$ & $8.2 \pm 7.7$ & $5.6 \pm 4.8$ & $\underline{0.002}$ & $5.9 \pm 4.5$ & $6.7 \pm 4.6$ & 0.645 \\
\hline Functional capacity & $125.1 \pm 1.1$ & $125.1 \pm 0.9$ & 1.000 & $124.6 \pm 2.4$ & $125.1 \pm 0.7$ & 0.427 \\
\hline
\end{tabular}

${ }^{t} \mathrm{DO}=$ direct order; $\mathrm{IO}=$ indirect order; ${ }^{*}$ student's t-test for independent samples.

Table 3. Descriptive and comparative analysis of the ACE-R, total ACE-R and total MMSE domains according to the assessment period (before and after) for the intervention and control groups. São Carlos, 2015.

\begin{tabular}{ccccccc}
\hline \multirow{2}{*}{$\begin{array}{c}\text { ACE-R Domains } \\
\text { mean } \pm \text { standard deviation }\end{array}$} & \multicolumn{3}{c}{ Intervention Group } & \multicolumn{3}{c}{ Control Group } \\
\cline { 2 - 7 } & BEFORE & AFTER & $p$ value $^{*}$ & BEFORE & AFTER & $p$ value $^{*}$ \\
\hline Guidance/care & $16.7 \pm 1.5$ & $17.5 \pm 1.1$ & 0.111 & $17.1 \pm 1.1$ & $17.4 \pm 0.9$ & 0.481 \\
Memory & $21.7 \pm 3.8$ & $22.1 \pm 3.3$ & 0.497 & $18.4 \pm 3.0$ & $19.7 \pm 3.1$ & 0.231 \\
Verbal fluency & $12.6 \pm 1.2$ & $12.6 \pm 1.7$ & 1.000 & $12.4 \pm 1.5$ & $12.4 \pm 1.7$ & 1.000 \\
Language & $24.6 \pm 1.2$ & $24.8 \pm 1.3$ & 0.499 & $25.1 \pm 1.1$ & $25.2 \pm 1.0$ & 0.740 \\
Visual and spatial & $14.5 \pm 1.6$ & $15.3 \pm 1.1$ & $\underline{0.022}$ & $14.6 \pm 1.9$ & $14.8 \pm 1.9$ & 0.851 \\
ACE-R & $89.3 \pm 4.1$ & $92.5 \pm 5.1$ & $\underline{0.082}$ & $88 \pm 5.8$ & $89.8 \pm 6.1$ & 0.413 \\
MMSE (ACE-R) & $27.9 \pm 2.1$ & $28.3 \pm 2.8$ & 0.559 & $27.7 \pm 1.7$ & $27.9 \pm 1.6$ & 0.748 \\
\hline
\end{tabular}

* student's t-test for paired samples. 


\section{DISCUSSION}

In the present study, the two groups (IG and CG) mostly contained elderly (60 years or more), retired, married and highly-educated women. A possible explanation for the predominance of female participants in these type of groups is the different nature of the aging process among women and how they perceive these differences. Women tend to be more interested in cultural activities whereas men are more interested in political issues. ${ }^{16}$ In addition, since the subjects were recruited from within the UATI, the profile of younger elderly (between 60 and 75 years) married, highly-educated women with a good income corroborates previous studies that described the participants of these programs. ${ }^{17-20}$

In the present study, CS was able to improve levels of visual and spatial function, as well as depression and anxiety symptoms. It is known that spatial perceptions can be affected by education levels. When performing visual tasks, individuals with less education require more time and commit more errors (finding less targets) than those with a higher level of education. ${ }^{21}$ This explains the improvement in this domain in the sample studied, given that a higher level of education can be directly correlated to easier learning. Furthermore, as a consequence of their higher level of education, these people may have performed less physical work in their lives and had greater access to health services, which led to them exhibiting better physical health conditions and a satisfactory memory performance, as previously discussed in the literature. ${ }^{4}$

According to the World Health Organization, ${ }^{22}$ depression is a psychiatric illness, in which the patient exhibits a deteriorating mood, reduced energy and decreased activity. Alterations to the individual's capacity to experience pleasure have also been confirmed, together with a loss of interest, low concentration levels and (usually) significant fatigue, even after exerting minimal effort. The most common symptoms are sleep disorders and a reduced appetite. Depressed individuals almost always experience reductions in self-esteem and self-confidence, as well as frequent feelings of guilt and/or worthlessness, even when depression symptoms are mild. ${ }^{23}$

Depression involves a series of impairments to the functioning of the individual. A study by Carneiro et al. ${ }^{24}$ sought to investigate social skills, social support, quality of life and depression among elderly individuals in the University for Senior Citizens of the Universidade do Estado do Rio de Janeiro (Rio de Janeiro State University) (UnATI/UERJ). The authors analyzed both family and institutional environments and found that the elderly individuals in the institutionalize group exhibited significantly higher levels of depression than those in the family group. The authors concluded that depression symptoms are associated with worse social functioning and a lower quality of life.

It is believed that cognitive damage is characteristic of depression and depressed individuals tend to exhibit worse psychosocial functioning. When combined with old age, the fear that something awful might happen, health issues, financial problems and the fear of abandonment, it can lead to anguish, anxiety and concern for the elderly individual, which consequently worsen their depression. ${ }^{25}$ In addition, since the individual has experienced the losses (including cognitive losses) and bodily changes associated with aging, a grieving process is commonly experienced, which may intensify the symptoms of depression and anxiety. ${ }^{26}$ Thus, interventions that can predict cognitive impairment and minimize depressive symptoms are of great interest to the scientific community. ${ }^{7}$

Cognitive stimulation involves a variety of group activities and discussions that seek to achieve a general improvement in the cognitive and social functioning of the paticipants. ${ }^{27}$ Cognitive stimulation activities and a more active and socially-engaged lifestyle can have positive effects on cognition and may prevent cognitive decline and depression. ${ }^{28}$

A significant decrease was recorded in the symptoms of anxiety exhibited by the participants in the IG after the intervention used in the present study. One of the hypotheses proposed for this 
result was their participation in the cognitive stimulation group sessions, where they felt valued and were stimulated to modify their lifestyle, expand their knowledge and feel equal (or even better) than other people of the same age. ${ }^{4}$

Valentijin et al. ${ }^{6}$ compared strategies of cognitive stimulation for groups and individuals. The authors found that the individuals exhibited no improvements in specific tests, although their anxiety levels did decrease. Conversely, group memory training was beneficial in terms of the specific tests and anxiety levels, since the participants had the opportunity to share their experiences (positive and negative) in relation to memory. The individuals who participated in groups also witnessed more examples and were more motivated than those who trained on their own. The value of group cognitive stimulation activities for healthy elderly individuals was also reported in a recently-published systematic review and meta-analyis. ${ }^{29}$

Although the present study did not achieve statistically significant improvements for the cognitive domains of attention, memory, verbal fluency, language and executive functions, there was a discreet improvement in these domains when comparing the values recorded before and after the intervention. The participants of the present study were active, healthy individuals, who recorded high scores for cognitive performance in the pre-test, which may have affected these results.

A study by Youn $e t$ al..$^{30}$ also demonstrated the effectiveness of cognitive training in a healthy sample, with positive results for the memory of elderly individuals. Carvalho, Neri and Yassuda ${ }^{31}$ reported improvements in episodic memory and more use of the strategies learned in the experimental group. Another study demonstrated an improved cognitive performance in a healthy sample, in terms of their performance in tests of attention, memory, verbal memory, oral language, written language and constructional apraxia, when comparing the results of the experimental and control groups. ${ }^{4}$ The results of a literature review demonstrated the promising and significant effects of CS on healthy elderly individuals, particularly in relation to memory, attention, executive function and the speed of processing. ${ }^{32}$

Another study ${ }^{33}$ sought to ascertain and compare the performance of adults and elderly individuals $(\mathrm{n}=79)$ in tests of attention, memory, mood and metamemory before and after 20 sessions of multidisciplinary cognitive stimulation in a large hospital in the city of São Paulo. The authors reported improvements in the performance of the participants in the attention and memory tests $(p<0.001)$, as well as a reduction in symptoms of depression $(p=0.014)$ and anxiety $(p<0.001)$.

Therefore, literature contains divergent findings. In most studies, the participants in cognitive stimulation workshops exhibited significant improvements in these domains. However, many of these studies used different assessment techniques and were conducted in different regions, with specific peculiarities for each sample studied. Thus, it is difficult to adequately compare these results with other studies in this area.

In general, the improvement in cognitive function recorded in the present study can be explained by cognitive plasticity, which refers to increased learning (note the diferences in the pre- and post-test scores), as indicated by the improved performance after receiving instructions and practicing the task. Cognitive functions are sensitive to manipulation strategies and can benefit from the effects of cognitive stimulation. ${ }^{34}$

Another possible explanation for these results could be the fact that the engagement in these training sessions led to the activation of the cognitive function as a whole, due to the constant practice of exercises and the stimulation of the development of activities in the home that involved memory, attention and executive functions. Another hypothesis is that the simple fact of being in a stimulating and collective environment improved the participants' cognition in several domains. This hypothesis was previously suggested by Marioni et al., who confirmed the correlation between participation in social, physical and intellectual activities and increased (or stable) cognitive capacity. 
Continuous learning is essential in order to remain healthy in old age. Gerontologists have provided several arguments in favor of the promotion of an integrated social life for the elderly. These include the new information learned at cognitive stimulation workshops, which is important in relation to the promotion of health, the prevention of disabilities and the maintenance of cognitive capacity and quality of life. . $^{8,35}$ These conditions are associated with the concept of successful aging. The educational opportunities involved in workshops are important antecedents of evolutionary gains in old age, since they seem to intensify social contact, while promoting the exchange of experiences/knowledge and personal improvements.

\section{CONCLUSION}

The results of the present study suggest that group CS interventions have a beneficial effect on visual and spatial functions, while also improving symptoms of depression and anxiety. The limitations of the present study include the fact that it was not randomized and it was impossible to control the variables related to the living conditions of the subjects, as well as their participation in other activities in the UATI. It is important to stress that this study was conducted using a relatively homogenous sample, with a high level of education and a satisfactory socioeconomic situation, which may not reflect the reality of many elderly individuals.

Brazilian studies of cognitive stimulation in adults and the elderly remain incipient, particularly those that focus on cognitive abilities. Therefore, other studies are suggested to explore the influence of these impact variables on the improvement of cognitive functions.

It is hoped that the results of the present study promote cognitive stimulation practices, thereby improving social inclusion and creating a sense of mutual cooperation between those involved, particular the elderly population. It is also hoped that these practices are disseminated in health and education services.

\section{ACKNOWLEDGMENT}

The São Paulo Amparo Research Foundation (Fundação de Amparo à Pesquisa do Estado de São Paulo - FAPESP) for financial support to work. Process 2014/18829-4.

\section{REFERENCES}

1. Silva TBLD, Oliveira ACVD, Paulo DLV, Malagutti, MP, Danzini VMP,Yassuda MS. Treino Cognitivo para idosos baseado em estratégias de categorização e cálculos semelhante a tarefas do cotidiano. Rio de Janeiro. Rev Bras Geriatr Geront 2011;14(1):65-74.

2. Canineu PR, Samara AB, Stella F. Transtorno Cognitivo Leve. In: Freitas EV, Py L,organizadoras. Tratado de Geriatria e Gerontologia. 3. ed. Rio de Janeiro: Guanabara Koogan; 2011. p. 169-77.

3. Simon SS, Riberto MPO. Comprometimento cognitivo leve e reabilitação neuropsicológica: uma revisão bibliográfica. Psic Rev 2011;20(1);93-122.
4. Irigaray TQ, Gomes I Filho, Schneider RH. Efeitos de um treino de atenção, memória e funções executivas na cognição de idosos saudáveis. Psicol Reflex Crit 2012;25(1):188-201.

5. Yassuda MS, Batistoni SST, Fortes AG, Neri AL. Treino de memória no idoso saudável: Benefícios e mecanismos. Psicol Reflex Crit 2006;9(3):470-81.

6. Valentijn SA, Van Hooren SA, Bosma H, Touw DM, Jolles J, Van Boxtel, et al. The effect of two types of memory training on subjective and objective memory performance in healthy individuals aged 55 years and older: a randomized controlled trial. Patient Educ Couns 2005;57(1):106-14. 
7. Rock PL, Roiser JP, Riedel WJ, Blackwell AD. Cognitive impairment in depression: a systematic review and metaanalysis. Psychol Medi 2014;44(10):2029-40.

8. Marioni RE, Proust-Lima C, Amieva H, Brayne C, Matthews FE, Dartigues JF, et al. Social activity, cognitive decline and dementia risk: a 20 -year prospective cohort study. BMC Public Health 2015;15(1):1089.

9. Castro PC, Aciole GG, Driusso P, Oishi J. Papel do fisioterapeuta na Universidade Aberta da Terceira Idade de São Carlos. Estud Interdiscipl Envelhec 2014;19(1):287-305.

10. Carvalho VA, Caramelli P. Brazilian adaptation of the Addenbrooke's cognitive examination-revised (ACE-R). Dement Neuropsychol 2007;1(2):212-16.

11. Carvalho VA, Barbosa MT, Caramelli P. Brazilian version of Addenbrooke's Cognitive Examination in the diagnosis of mild Alzheimer Disease. Cog Behav Neurol 2010; 23(1):8-13.

12. Weschsler D. Weschsler Adult Intelligence Scale-Revised. WAIS-R Manual. San Antonio: Psychological Corporation; 1981. p. 132-204.

13. Cunha JA. Manual da versão em português das Escalas Beck. São Paulo: Casa do Psicólogo; 2001.

14. Beck AT. Inventory for Measuring Depression. Arch Gen Psychiatr 1961;4:53-6.

15. Riberto M, Miyazaki MH, Jucá SS, Sakamoto H, Potiguara P, Pinto N, et al. Validação da Versão Brasileira da Medida de Independência Funcional. Acta Fisiátrica 2004;11(2):72-6.

16. Barreto KML, Carvalho EMFD, Falcão IV, Lessa FJD, Leite VMM. Perfil sócio-epidemiológico demográfico das mulheres idosas da Universidade Aberta à Terceira Idade no estado de Pernambuco. Rev Bras Saúde Mater Infant 2003;3(3):339-54.

17. Carvalho-Loures M, Celeno-Porto C, AlvesBarbosa M, Freire-Filha LG. Women's quality of life: University of the Third Age, Goiás, Brazil. Rev Salud Pública 2010;12(3):391-401.

18. Ordonez TN, Batistoni SS, Cachioni M. Depressive symptoms in older adults studying at a third age open university. Rev Esp Geriatr Gerontol [Internet] 2011 [acesso em 15 jun 2015];46(5):250-5. Disponível em: http://www.unboundmedicine.com/ ebm/journal/ Revista_espanola_de_geriatria_y_gerontologia

19. Sonati JG, Modeneze DM, Vilarta R, Maciel ES, Boccaletto EM, Da Silva CC. Body composition and quality of life (QoL) of the elderly offered by the "University Third Age" (UTA) in Brazil. Arch Gerontol Geriatr 2011;52(1):31-5.
20. Zielińska-Więczkowska H, Ciemnoczołowski W, Kędziora-Kornatowska K, Muszalik M. The sense of coherence (SOC) as an important determinant of life satisfaction, based on own research, and exemplified by the students of University of the Third Age (U3A). Arch Gerontol Geriatr 2012;54(1):238-41.

21. Owsley C, Mcgwin G. Association between visual attention and mobility in older adults. J Am Geriatr Soc 2004;52(11):1901-6.

22. Organização Mundial Da Saúde. Envelhecimento ativo: uma política de saúde. Gontijo S, tradutor. Brasília,DF: Organização Pan-Americana da Saúde; 2008.

23. American Psychiatric Association. Diagnostic and Statistical Manual of Mental Disorders. 5th Ed. Arlington: American Psychiatric Association; 2013.

24. Carneiro RS, Falcone E, Clark C, Del Prette Z, Del Prette A. Qualidade de vida, apoio social e depressão em idosos: relação com habilidades sociais. Psicol Reflex Crit [Internet] 2007 [acesso em 04 set 2015];20(2):229-37. Disponível em: http://www.scielo. br/pdf/prc/v20n2/a08v20n2.pdf

25. Disponível em http://www.scielo.br/ scielo.php?script $=$ sci_arttext\&pid=S010279722007000200008\&lng=en\&tlng=pt.

26. Chaves ECL, Paulino CFE, Souza VHS, Mesquita AC, Carvalho FS, Nogueira DA. Qualidade de vida, sintomas depressivos e religiosidade em idosos: um estudo transversal. Texto Contexto Enferm [Internet] 2014 [acesso em 03 jul 2015];23(3):648-55. Disponível em: http://www.scielo.br/scielo.php?script=sci_ arttext\&pid=S0104-07072014000300648\&lng=pt. http://dx.doi.org/10.1590/0104-07072014001000013.

27. Cocentino JMB, Viana TC. A Velhice e a Morte: reflexões sobre o processo de luto. Rev Bras Geriatr Gerontol 2011;14(3):591-600.

28. Claire L, Woods R. Cognitive training and cognitive rehabilitation for people with early-stage Alzheimer's disease: a review. Neuropsychol Rehabil 2004;14:385-401.

29. Kelly ME, Loughrey D, Lawlor BA, Robertson IH, Walsh C, Brennan, S. The impact of cognitive training and mental stimulation on cognitive and everyday functioning of healthy older adults: a systematic review and meta-analysis. Ageing Res Rev 2014;15:28-43.

30. Youn JH, Lee JY, Kim S, Ryu SH. Multistrategic Memory Training with the Metamemory Concept in Healthy Older Adults. Psychiatry Investig 2011;8(4):354-61. 
31. Carvalho FCR, Neri AL, Yassuda MS. Treino de memória episódica com ênfase em categorização para idosos sem demência e depressão. Psicol Reflex Crit [Internet] 2010 [acesso em 15 set 2015];23(2): 317-23.Disponível em: http://www.scielo.br/scielo. php?script=sci_arttext\&pid=S0102-79722010000200014

32. Tardif S, Simard M. Cognitive stimulation programs in healthy elderly: a review. Int J Alzheimers Dis 2011:1-13.

33. Gil G, Busse AL, Shoji FT, Martinelli PD, Mercadante EF. Efeitos de um programa de estimulação cognitiva multidisciplinar intergeracional. Rev Bras Geriatr Gerontol 2015;18(3):533-43

34. Craik FLM, Gordon W, Palmer H, Binns M, Edwards $\mathrm{M}$, Bridges $\mathrm{K}$, et al. Cognitive rehabilitation in the elderly: effects on memory. J Int Neuropsychol Soc 2007;13(1):132-42.

35. Oliveira CS, Costa SRR, Santos ICL, Lemos CES. Oficina de educação, memória, esquecimento e jogos lúdicos para a Terceira Idade. Rev Ciênc Extensão 2012;8(1):8-17.

Received: November 11, 2015

Reviewed: April 01, 2016

Accepted: June 15, 2016 